\title{
Study on Auto-DR and Pre-cooling of Commercial Buildings with Thermal Mass in California
}

\author{
Rongxin Yin, Peng Xu, Mary Ann Piette, Sila Kiliccote \\ Lawrence Berkeley National Laboratory
}

January 2010 


\section{DISCLAIMER}

This document was prepared as an account of work sponsored by the United States Government. While this document is believed to contain correct information, neither the United States Government nor any agency thereof, nor The Regents of the University of California, nor any of their employees, makes any warranty, express or implied, or assumes any legal responsibility for the accuracy, completeness, or usefulness of any information, apparatus, product, or process disclosed, or represents that its use would not infringe privately owned rights. Reference herein to any specific commercial product, process, or service by its trade name, trademark, manufacturer, or otherwise, does not necessarily constitute or imply its endorsement, recommendation, or favoring by the United States Government or any agency thereof, or The Regents of the University of California. The views and opinions of authors expressed herein do not necessarily state or reflect those of the United States Government or any agency thereof or The Regents of the University of California. 


\title{
Study on Auto-DR and Pre-cooling of Commercial Buildings with Thermal Mass in California
}

\author{
Rongxin Yin, Peng Xu, Mary Ann Piette, Sila Kiliccote \\ Commercial Building Systems Group, Environmental Energy Technologies Division, \\ Lawrence Berkeley National Laboratory, 1 Cyclotron Road, MS90R3111, Berkeley, CA 94720
}

\begin{abstract}
This paper discusses how to optimize pre-cooling strategies for buildings in a hot California climate zone with the Demand Response Quick Assessment Tool (DRQAT), a building energy simulation tool. This paper outlines the procedure used to develop and calibrate DRQAT simulation models, and applies this procedure to eleven field test buildings. The results of a comparison between the measured demand savings during the peak period and the savings predicted by the simulation model indicate that the predicted demand shed match well with measured data for the corresponding Auto-Demand Response (Auto-DR) days. The study shows that the accuracy of the simulation models is greatly improved after calibrating the initial models with measured data. These improved models can be used to predict load reductions for automated demand response events. The simulation results were compared with field test data to confirm the actual effect of demand response strategies. Results indicate that the optimal demand response strategies worked well for most of the buildings tested in this hot climate zone.
\end{abstract}

Keywords: Pre-cooling; Demand response; Thermal mass; Auto-DR; Demand shed; Peak demand

\section{Introduction}

The potential for utilizing building thermal mass for load shifting and peak demand reduction has been demonstrated in a number of simulation, laboratory, and field studies. Rabl et al. [1] developed a date-based dynamic model to simulate the effect of different thermostat control strategies for reducing peak demand. Morris et al. [2] studied two optimal dynamic building control strategies in a representative room in a large office building. The experiments showed the reduction in peak cooling load to be as much as $40 \%$. Keeney et al. [3] developed a building cooling control strategy and conducted an experiment in a large office building. They found the pre-cooling strategy could limit the peak cooling load to $75 \%$ of the cooling capacity. $\mathrm{Xu}$ et al. [4] demonstrated the potential for reducing peak electrical demand in moderate-weight commercial buildings by modifying the control of the heating, ventilation and air-conditioning (HVAC) system. Field tests showed the chiller power was reduced by $80-100 \%$ (1-2.3 $\mathrm{W} / \mathrm{ft}^{2}$ ) during the peak period without causing thermal comfort complaints. Xu et al. [5] conducted a series of field tests in two commercial buildings in Northern California to investigate the effects of various pre-cooling and demand shed strategies. Field tests demonstrated the potential to reduce the cooling load $25-50 \%$ in peak hours and the importance of discharge strategies to avoid rebounds. Braun [6] presented an overview of research related to the use of building thermal mass for shifting and reducing peak cooling loads in commercial buildings and provided specific results obtained through simulations, laboratory tests and field studies.

Demand response (DR) is a process of managing customer consumption of electricity in response to supply conditions to reduce the electricity costs or improve the system reliability. Demand shifting refers to a shift in the demand curve, brought about by consuming electricity at a different time to benefit from time-of-use rates, which can be achieved by utilizing thermal energy storage such as ice storage or building thermal mass. Demand shedding is a temporary reduction of peak electric demand for achieving economic savings. N. Motegi et al. [7] provided an introduction to commercial building control strategies 
and techniques for demand response such as control strategies for HVAC, lighting and other miscellaneous building end-use systems. This report also summarized information from field demonstrations of DR programs in commercial buildings.

This paper describes the development of simulation models for eleven commercial buildings in a hot climate zone in California, the use of DRQAT for evaluating DR potential in these buildings, and how to optimize DR strategies developed by LBNL. DRQAT is based on EnergyPlus simulations of prototypical buildings, developed by J. Huang et al. [8], and HVAC equipment. It incorporates prototypical buildings and equipment and allows the user to specify a relatively small number of important parameters in order to make a quick assessment of DR strategies that use a building's thermal mass. This tool was used to optimize the temperature control strategies in eleven office buildings located in a hot climate zone in California in 2008. Optimal demand response strategies, or those that maximize demand response savings for these buildings, were determined through comparison of simulation results of pre-cooling strategies with the measured data from the same strategies implemented in the buildings on test event days. Xu et al. [9] conducted a series of simulations and strategy analyses by using EnergyPlus to evaluate various demand response strategies. The initial models were revised and the parameters were adjusted to ensure the hourly simulation profile matched the measured data.

\section{Development of Optimal Pre-cooling Strategies}

Figure 1 shows the general procedure for developing and calibrating the DRQAT simulation models for the field test buildings. All of the models were calibrated with the measured data to meet the acceptable tolerance levels developed in ASHRAE Guideline 14 [10]. Based on the calibrated baseline models, various demand response strategies were simulated to determine how to discharge thermal mass efficiently and smoothly with no rebound in electricity demand. 


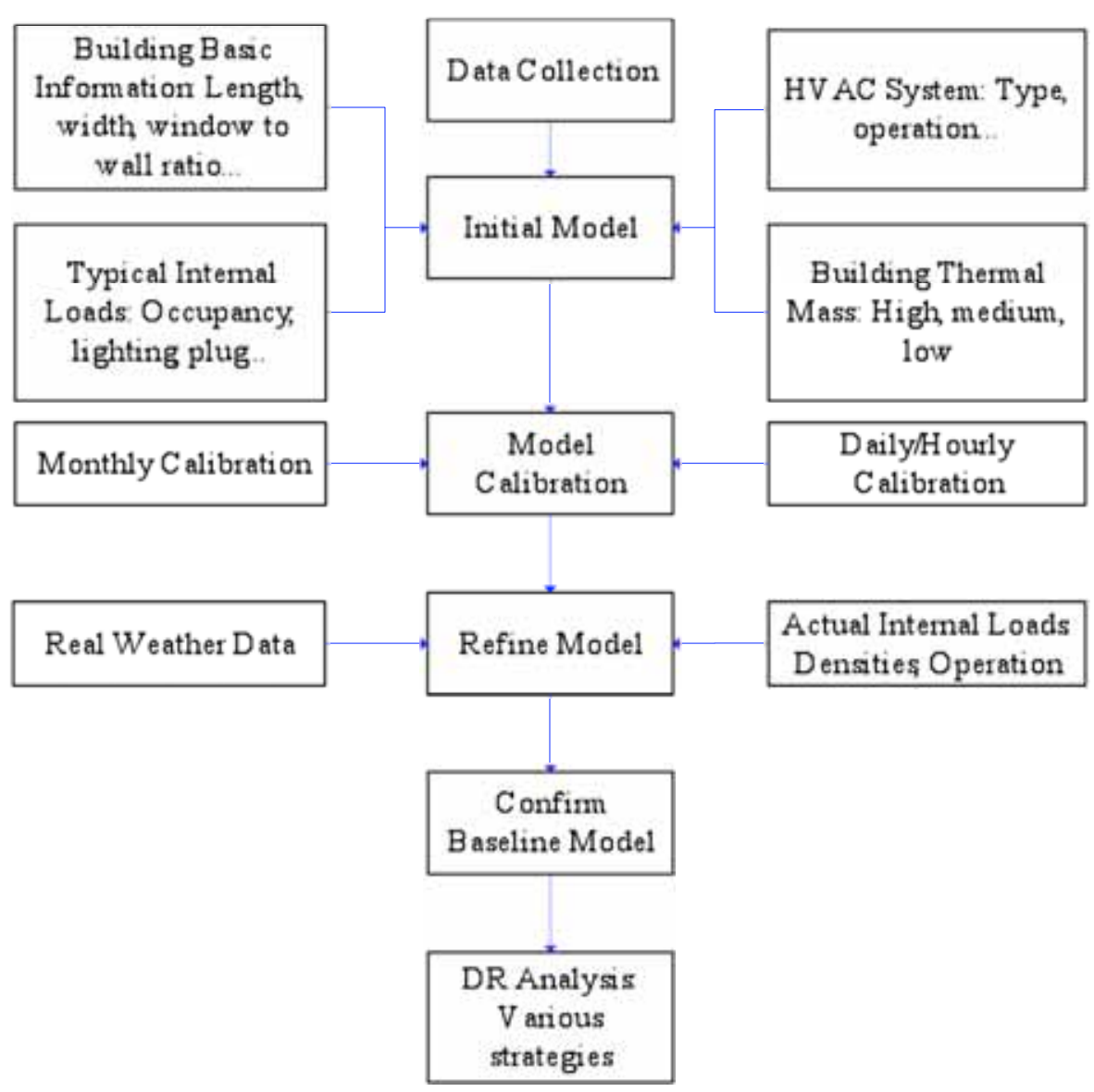

Figure 1 Development and Calibration of the Simulation model by Using DRQAT

J. Yoon et al. [11] developed a systematic calibration method using a "base load analysis approach" that calibrates a building energy performance model with a combination of monthly utility billing data and sub-metered data. The results of the case study indicated that the approach provided a reliable and accurate simulation of the monthly and annual building energy requirements. Reddy et al. [12, 13] proposed a general methodology for calibrating detailed building energy simulation programs based on performance data and applied this methodology to three case study office buildings. Pan et al. [14] conducted simulation model calibration step by step in a high-rise commercial building based on the approach proposed in ASHRAE Guideline 14-2002 [10]. Norford et al. [15] presented a commonsense procedure for calibrating a DOE-2 computer model of a commercial building, and identified the major building loads in the building including lighting and equipment. The results from the calibrated DRQAT simulation models were within the acceptable tolerance levels of the measured data.

\subsection{Simulation Model Development}

The initial simulation models were developed after completing field data collection. The quantity and accuracy of the collected data, such as information about the building envelope, the densities and operating schedules of occupancy, lighting and plug loads, HVAC system characteristics, and building operation have a direct impact on the accuracy of the simulation results. Therefore, the more abundant and accuracy the data, the more accurately the models can predict the peak load reduction.

\subsubsection{Inputs for the Initial Simulation Model}


Table 1 presents a summary of the building descriptions and the internal loads of the eleven commercial buildings. The building audits provided general information, such as number of stories, gross area, window-to-wall ratio and other related information. The building orientation, the length, and the width of each building were measured with Google Earth, which offers maps and satellite images of the buildings. The data collected suggested most of the information related to schedules and demand intensities was not available for these facilities and end-use sub-metering data was not available. Therefore, the authors used default values for the initial model because the buildings were "typical" office buildings.

Table 1 Initial Simulation Model Input - Building Information

\begin{tabular}{lccccccc}
\hline Site No. & $\begin{array}{c}\text { Gross Area } \\
\left(\mathrm{m}^{2}\right)\end{array}$ & Length $(\mathrm{m})$ & Width $(\mathrm{m})$ & $\begin{array}{c}\text { Floor } \\
\text { Height }(\mathrm{m})\end{array}$ & WWR_SN & WWR_EW & $\begin{array}{c}\text { Building } \\
\text { Orientation }\end{array}$ \\
\hline$\# 1$ & $6,405.50$ & 91.40 & 35.10 & 3.70 & 0.50 & 0.50 & 45 \\
\hline$\# 2$ & $5,833.70$ & 91.40 & 32.00 & 3.70 & 0.50 & 0.50 & 315 \\
\hline$\# 3$ & $3,605.00$ & 82.30 & 21.30 & 3.70 & 0.50 & 0.50 & 45 \\
\hline$\# 4$ & $6,849.10$ & 62.50 & 27.40 & 3.70 & 0.25 & 0.25 & 315 \\
\hline$\# 5$ & $6,509.00$ & 53.30 & 30.50 & 3.70 & 0.60 & 0.60 & 0 \\
\hline$\# 6$ & $10,470.70$ & 64.00 & 27.40 & 3.70 & 0.60 & 0.60 & 0 \\
\hline$\# 7$ & $7,501.20$ & 76.20 & 33.50 & 3.70 & 0.40 & 0.40 & 0 \\
\hline$\# 8$ & $7,775.00$ & 128.00 & 30.50 & 3.70 & 0.40 & 0.40 & 45 \\
\hline$\# 9$ & $9,707.50$ & 106.70 & 30.50 & 3.70 & 0.40 & 0.40 & 45 \\
\hline$\# 10$ & $11,057.60$ & 61.00 & 45.70 & 3.70 & 0.40 & 0.40 & 0 \\
\hline$\# 11$ & $7,531.80$ & 106.70 & 35.10 & 3.70 & 0.30 & 0.30 & 45 \\
\hline
\end{tabular}

Notes

Floor Height: height of the single floor;

WWR_SN: window to wall ratio for south and north sides of the building;

$W W R \_E W$ : window to wall ratio for east and west sides of the building;

Building Orientation: building north axis is specified relative to true north and the value is specified in degrees from "true north" (Clockwise is positive).

Internal loads such as occupancy, lighting, and plug loads make up the majority of cooling loads in office buildings. Therefore, the densities and operating schedules of the internal loads can significantly influence the load profile of the whole building and HVAC system. Where the end-use sub-metering was not available for these eleven buildings, the internal occupancy, lighting and equipment was estimated based on the characteristics of typical office buildings. Table 2 presents the inputs of building internal loads for the initial simulation models and the plug density values for the calibrated model. With the information on building type and year of built, the lighting intensity was estimated using California's Energy Efficiency Standards for Residential and Non Residential Buildings [16]. The plug intensity was estimated at $8.1 \mathrm{~W} / \mathrm{m}^{2}\left(0.75 \mathrm{~W} / \mathrm{ft}^{2}\right)$, and occupancy intensity was $36.2 \mathrm{~m}^{2}\left(390 \mathrm{ft}^{2}\right)$ per person based on the characteristics of typical office buildings. The initial schedules for lighting, equipment and people were the same as typical operation of commercial buildings benchmark models developed by Torcellini et al. [17], as shown in Figure 2 and Figure 3. 
Table 2 Initial Simulation Model Input - Internal Loads

\begin{tabular}{|c|c|c|c|c|c|}
\hline \multirow{2}{*}{ Site No. } & \multirow{2}{*}{ Year Constructed } & \multirow{2}{*}{$\begin{array}{l}\text { Lighting Density } \\
\left(\mathrm{W} / \mathrm{m}^{2}\right)\end{array}$} & \multicolumn{2}{|c|}{ Plug Density $\left(\mathrm{W} / \mathrm{m}^{2}\right)$} & \multirow{2}{*}{$\begin{array}{c}\text { Occupancy } \\
\left(\mathrm{m}^{2} / \text { per person) }\right.\end{array}$} \\
\hline & & & Initial & Calibrated & \\
\hline \#1 & 1990 & 17.2 & 8.1 & 8.1 & 36.2 \\
\hline$\# 2$ & 1988 & 17.2 & 8.1 & 16.1 & 36.2 \\
\hline$\# 3$ & 1988 & 17.2 & 8.1 & 16.1 & 36.2 \\
\hline$\# 4$ & 1988 & 17.2 & 8.1 & 19.4 & 36.2 \\
\hline$\# 5$ & 1993 & 17.2 & 8.1 & 15.1 & 36.2 \\
\hline$\# 6$ & 1990 & 17.2 & 8.1 & 9.7 & 36.2 \\
\hline$\# 7$ & 2001 & 12.9 & 8.1 & 16.1 & 36.2 \\
\hline$\# 8$ & 2003 & 12.9 & 8.1 & 6.5 & 36.2 \\
\hline$\# 9$ & 2005 & 11.8 & 8.1 & 15.1 & 36.2 \\
\hline$\# 10$ & 2002 & 12.9 & 8.1 & 10.8 & 36.2 \\
\hline$\# 11$ & 1994 & 17.2 & 8.1 & 10.8 & 36.2 \\
\hline
\end{tabular}

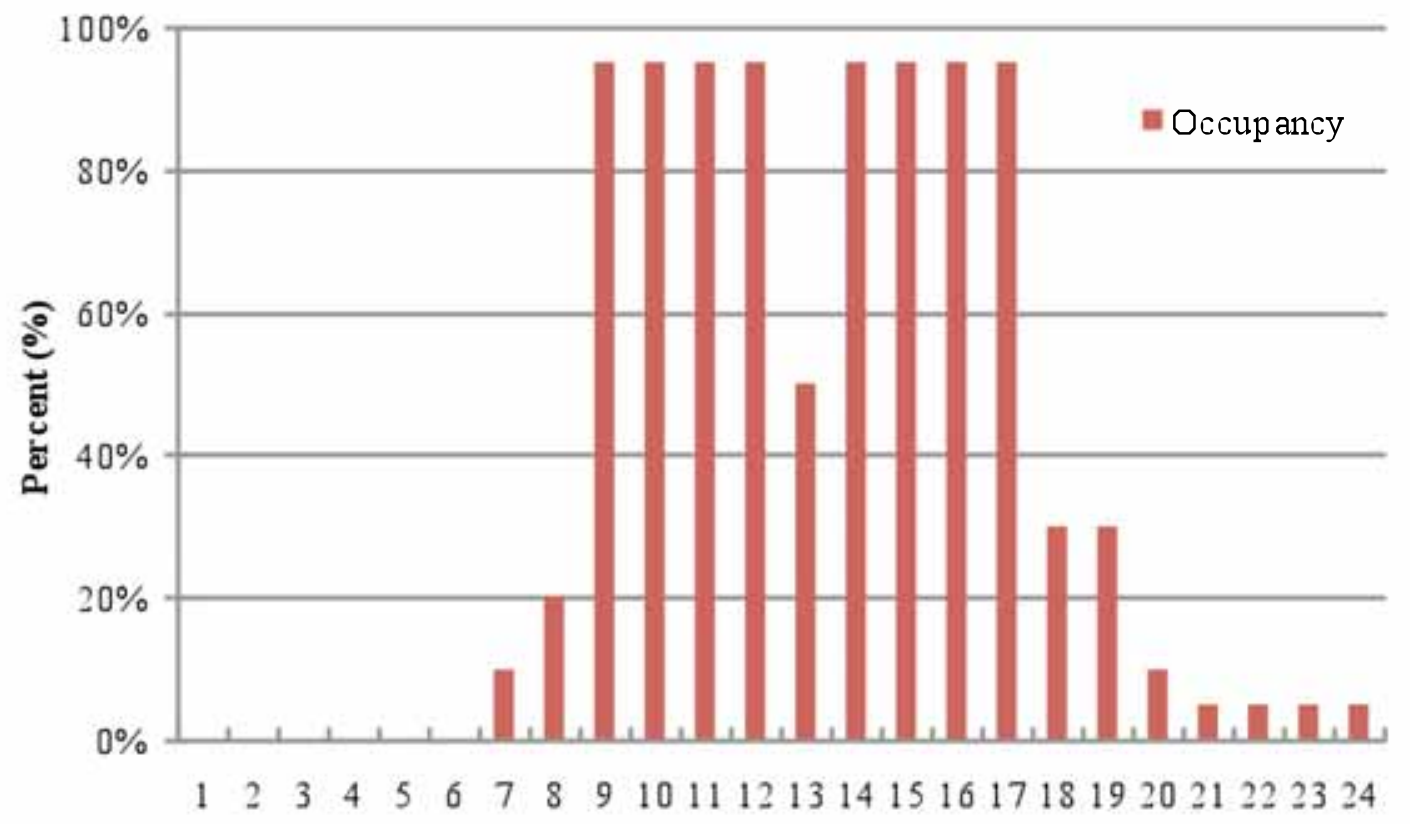

Figure 2 Initial Schedule of Occupancy on Weekdays 


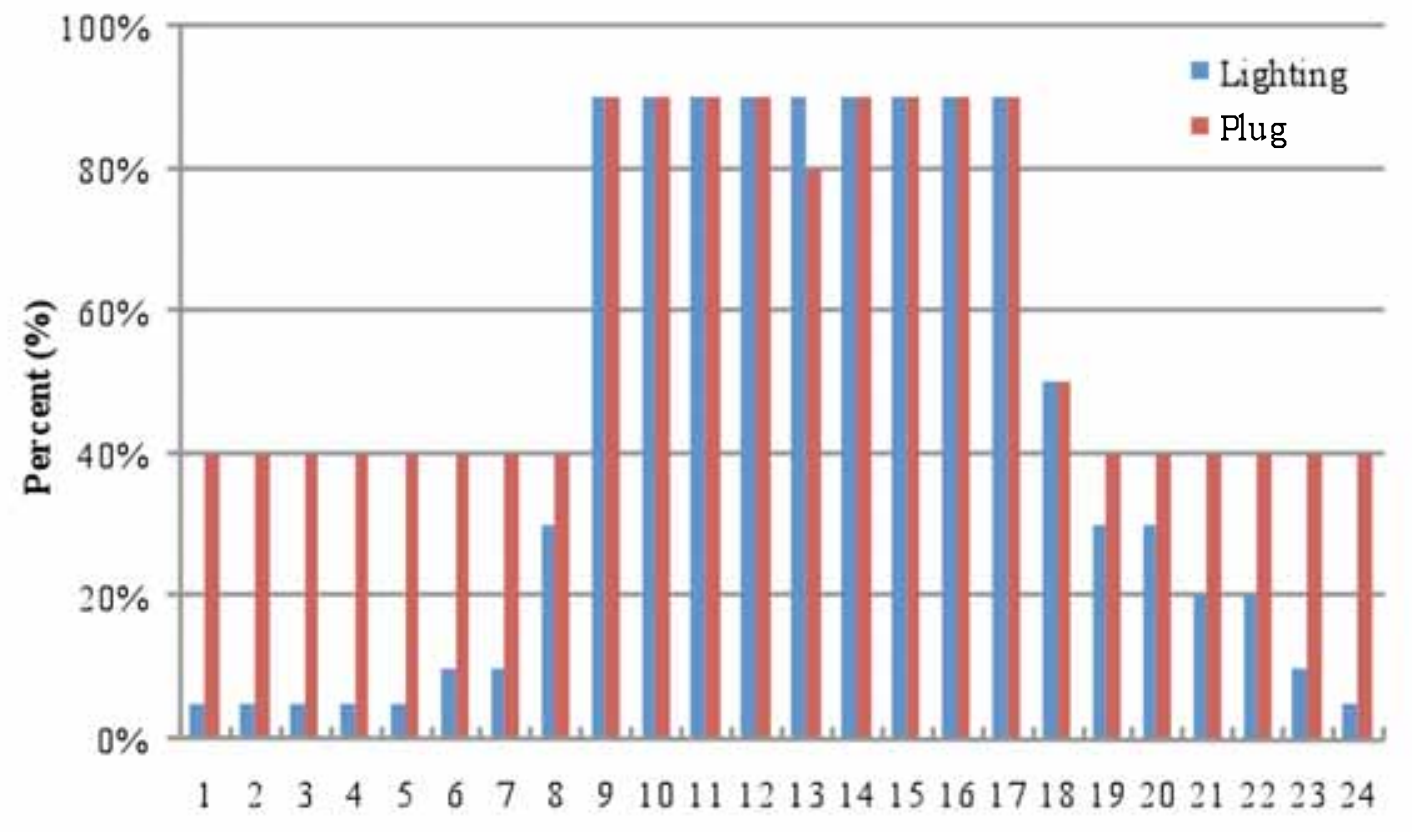

Figure 3 Initial Schedules of Lighting and Plug Power Densities on Weekdays

Each building has packaged rooftop units with variable-air-volume (VAV) distribution systems. On weekdays, the HVAC systems start between 6 am and 8 am, and turn off around $6 \mathrm{pm}$. The zone temperature for each building was monitored and controlled by a fully-equipped digital direct control (DDC) system, which enables various global zone temperature reset strategies for demand response analysis. The normal zone temperature setpoints were about $25^{\circ} \mathrm{C}\left(77^{\circ} \mathrm{F}\right)$ in the summer period.

\subsubsection{Initial Simulation Results}

Using the information mentioned above, the initial DRQAT simulation models were developed for each building. The initial simulated model was calibrated with measured energy data. For each initial simulation model, the absolute and the relative difference between the simulation results and the measured data were calculated. The electric consumption predicted by the simulation models was compared to the buildings' monthly utility bills as well as to some spot measurements. The simulation results and measured data for each building from the summer of 2007 were compared on both a monthly and hourly basis. In order to compare the simulation results and measured data, both graphical methods and statistical techniques were applied to determine where the simulation results differed from the measured data. Haberl et al. [18] and Kreider et al. [19, 20] used statistical mean bias error (MBE) and coefficient of variation of the root mean squared error (CV(RMSE)) to evaluate the accuracy of the predicted results of the simulation model. Pan et al. [14] and Yoon et al. [11] also applied the criteria as shown in Table 3 into the calibration procedure for energy simulation of commercial buildings. Several calibration approaches and guidelines have been developed that use statistical techniques as part of the calibration process $[10,21]$. Table 3 presents the acceptable tolerance for monthly and hourly data calibration according to ASHRAE Guideline 14. The initial models were calibrated to achieve the acceptable monthly tolerances based on the required MBE and CV(RSME) then again calibrated based on hourly data to achieve a higher level of accuracy.

Table 3 Acceptable Calibration Tolerances [10]

\begin{tabular}{lll}
\hline Calibration Type & Index & Acceptable Value \\
\hline
\end{tabular}




\begin{tabular}{lcc}
\hline \multirow{2}{*}{ Monthly } & $\mathrm{MBE}_{\text {month }}$ & $\pm 5 \%$ \\
\cline { 2 - 3 } & $\mathrm{CV}\left(\mathrm{RSME}_{\text {month }}\right)$ & $15 \%$ \\
\hline \multirow{2}{*}{ Hourly } & $\mathrm{MBE}_{\text {month }}$ & $\pm 10 \%$ \\
\cline { 2 - 3 } & $\mathrm{CV}\left(\mathrm{RSME}_{\text {month }}\right)$ & $30 \%$ \\
\hline
\end{tabular}

The following criteria were used to assess the difference between the simulation results and the measured data. Mean Bias Error (MBE) indicates how well the energy consumption was predicted by the model as compared to the measured data. CV(RMSE) was used to determine how well a model matched the measured data while accounting for cancellation errors.

$$
\begin{aligned}
& \mathrm{MBE}_{\text {month }}(\%)=\left[\frac{(\mathrm{M}-\mathrm{S})_{\text {month }}}{\mathrm{M}_{\text {month }}}\right] \times 100 \% \\
& \mathrm{CV}\left(\mathrm{RMSE}_{\text {month }}\right)(\%)=\left[\frac{\mathrm{RMSE}}{\overline{\mathrm{M}}_{\text {month }}}\right] \times 100 \% \\
& \mathrm{RMSE}_{\text {month }}=\left\{\frac{\left[\sum_{\text {month }}(\mathrm{M}-\mathrm{S})_{\text {month }}^{2}\right.}{\mathrm{N}_{\text {month }}}\right\} \\
& \bar{M}_{\text {month }}=\frac{\sum\left(\mathrm{M}_{\text {month }}\right)}{\mathrm{N}_{\text {month }}}
\end{aligned}
$$

Where $\mathrm{M}$ is the measured electric consumption $(\mathrm{kWh})$ in one month, $\mathrm{S}$ is the simulated electric consumption $(\mathrm{kWh})$ during the same month, and $\mathrm{N}$ is the number of months in the field test period.

As shown in Figure 4, only two simulation models were within the required $\pm 10 \%$ tolerance before calibration. The simulated results for the other nine buildings were much higher or lower than the measured data, with some monthly MBE and CV(RMSE) values larger than 20\%. To ensure the model meets the acceptable tolerance and to better understand what was happening in the initial models, calibration of each building model's subsystems wasf required.

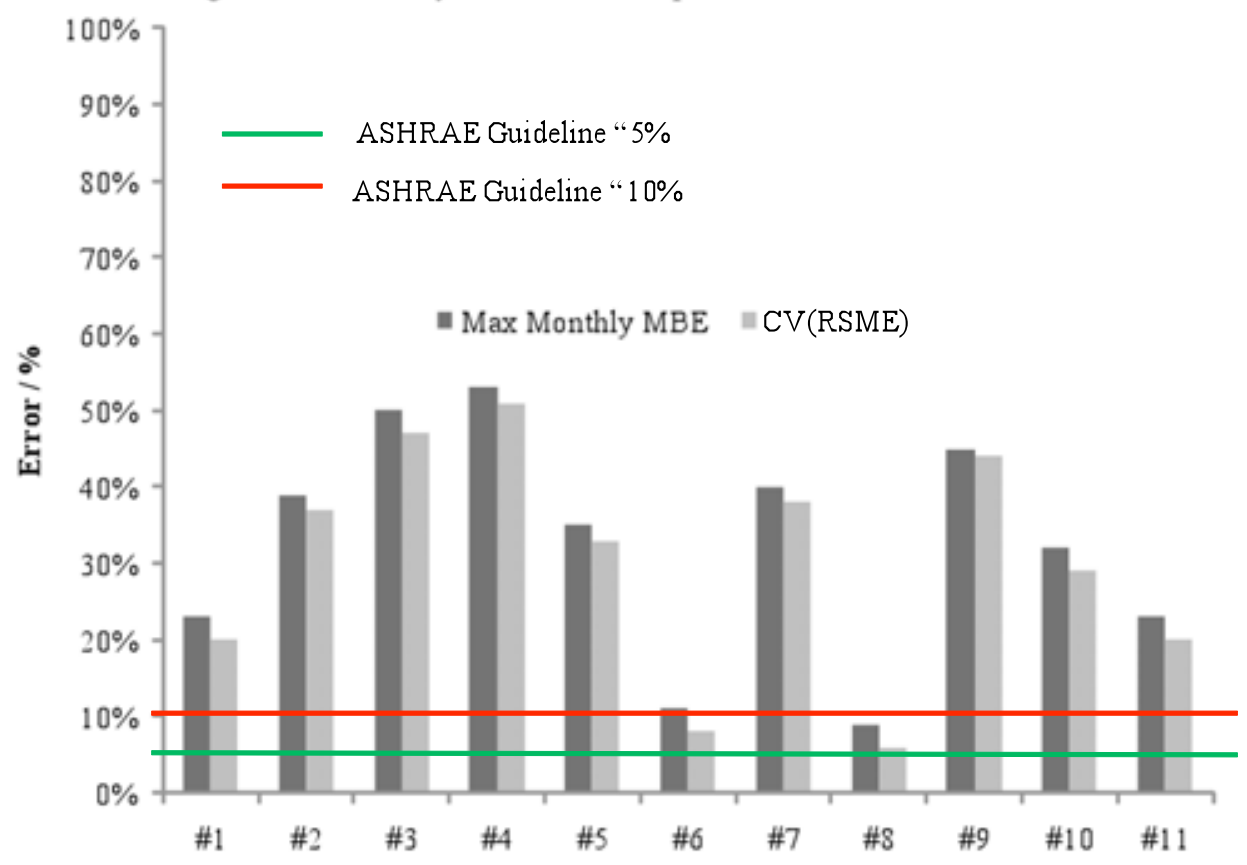

Figure 4 Difference of Monthly Electric Usage between Initial Model and Measured Data for 11 Buildings 


\subsubsection{Simulation Model Calibration}

Based on the whole building calibrated simulation approach developed in ASHRAE Guideline 14, attention was focused on the initial models' most important parameters, such as weather data and internal loads (lighting and plug loads). The weather data used in the initial models were TMY2 (Typical Meteorological Year) weather files available within DRQAT. Although some modelers have reported using typical year weather data for model calibration purposes, this approach was not recommended for this project as since the measured data used for the comparison occurred under actual weather conditions. During the calibration process, real weather data from 2007 and 2008 (from the EnergyPlus website) was applied to the simulation models.

After comparing the results of the initial simulation models and the measured data, it was determined that the plug loads assumed for most of the building models might be set too low, as shown in Table 2 . The occupancy, lighting and plug load schedules for different weekdays were assumed to be similar to each other throughout the year. Therefore, the densities and schedules of lighting and plug loads from the whole building electricity data were estimated for the heating period from November $1^{\text {st }} 2007$ to February $28^{\text {th }}$ 2008. The cooling plants were completely locked out during cooler weather, or when the maximum outside temperature was $12.8^{\circ} \mathrm{C}\left(55^{\circ} \mathrm{F}\right)$ or lower. Thus, the whole building power on these days only included lighting, plug and fan power. By analyzing the daily energy use of the building under theses cold weather conditions, the internal loads could be separated out from the whole building power. This method was applied to buildings where the heating sources were gas, steam, or hot water from other facilities. Significant differences were observed in the operation of lighting and plug loads between the initial models and real buildings, which led to high MBEs and CV(RMSE) for most of the models.

As mentioned earlier, Table 2 lists the building internal loads assumed for the initial and calibrated simulation models. The lighting and occupancy schedules were the same for both initial and calibrated models, while the plug load densities were changed for each building based on the electrical usage measured during the cold weather time period.

Office building \#8 offers an example of the model calibration procedure. Site \#8 is a typical office building: two-story with a large portion of the floor area covered with carpets. Large areas of each façade single pane with low-e glazing. The internal equipment and lighting loads were typical for office buildings and the occupancy density in the office area was approximately $390-400 \mathrm{ft}^{2}$ per person. Figure 5 and Figure 6 show the weekday and weekend/holiday lighting and plug loads schedules after calibration. The electric usage was constant during the unoccupied period. The occupancy schedule for the calibrated model was the same as that for the initial simulation model. 


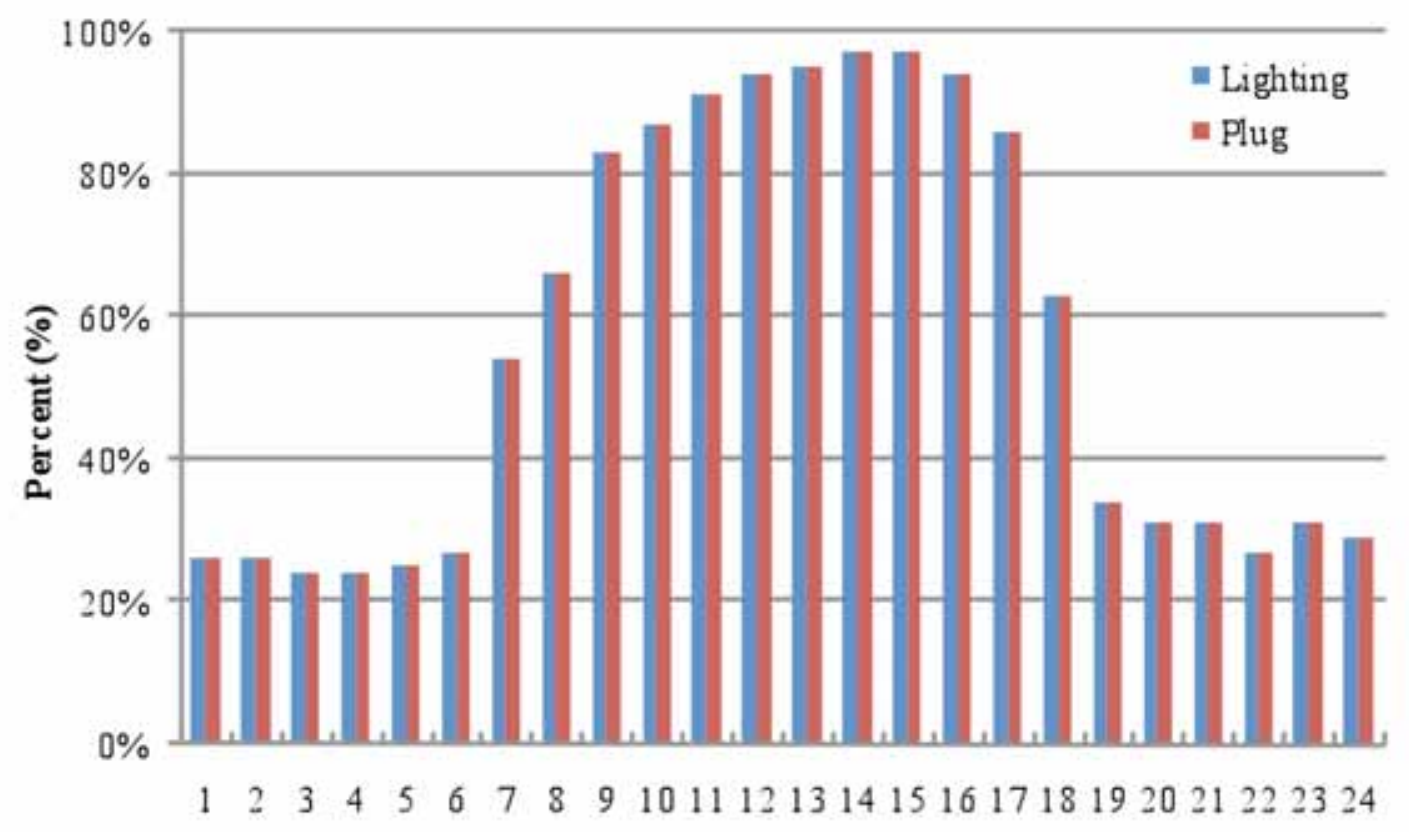

Figure 5 Calibrated Schedules of Lighting and Plug Densities on Weekdays

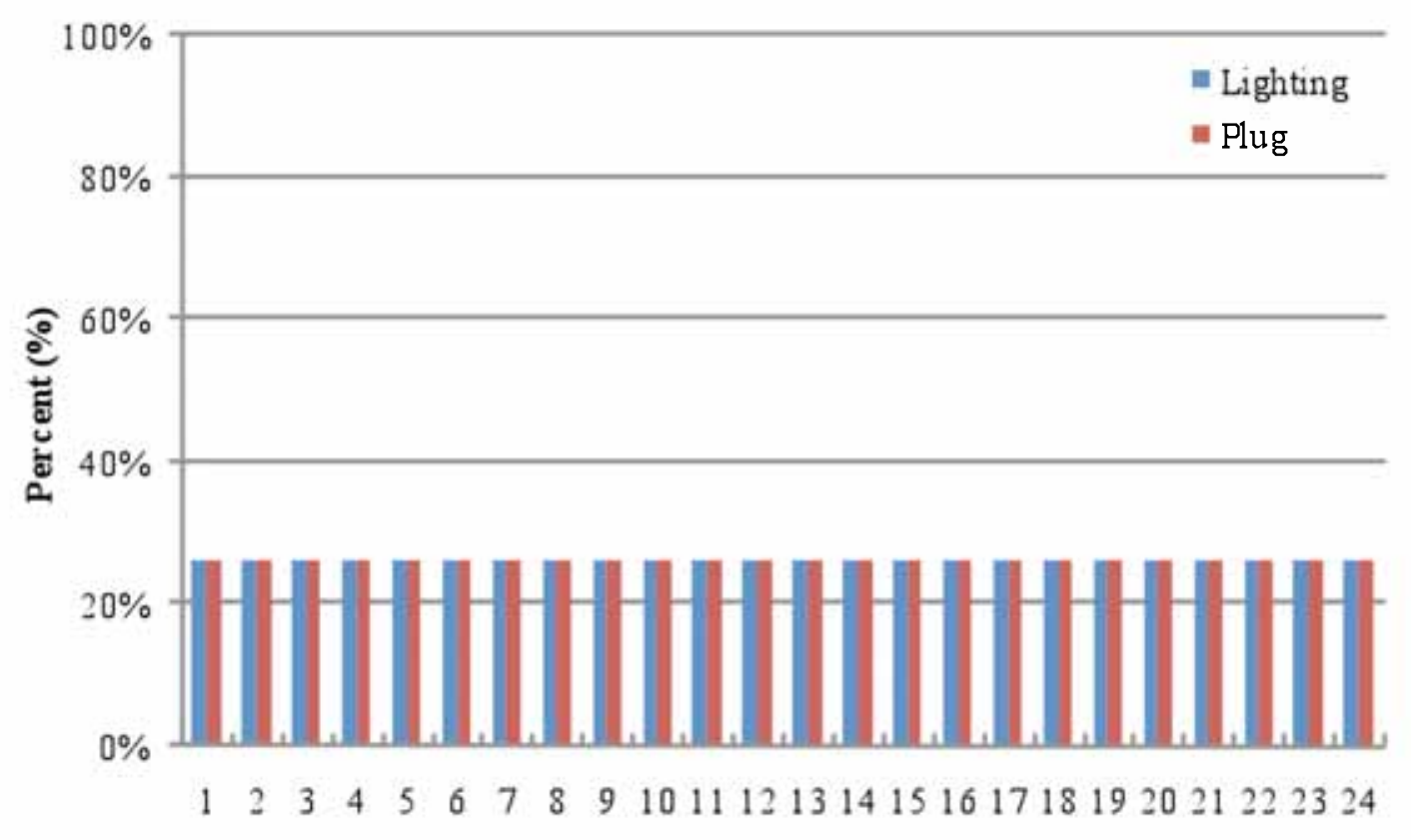

Figure 6 Calibrated Schedules of Lighting and Plug Densities on Weekend and Holidays

\subsubsection{Calibrated Simulation Models}

Figure 7 presents the monthly comparison between the calibrated simulation results and the measured data in 2007. The results indicate that monthly simulation results were almost within $\pm 5 \%$ of the measured data. Some monthly MBEs and CV(RMSE) were higher but still within $\pm 10 \%$. The acceptable 
calibration tolerances were achieved based on the hourly calibration criteria. Generally, the calibrated models provided reasonably good predictions of the monthly electrical usage as compared to the measurements. With respect to the hourly calibration, the lighting and plug load densities and schedules used in the models were constant throughout the year. In reality, they may vary slightly from day-to-day. Figure 8 compares the simulated and measured whole building electrical demand for building \#8 on weekdays from August $20^{\text {th }}$ to $24^{\text {th }}$. As shown in Figure 8, the simulated interval electrical demand and the measured data agree pretty well despite the discrepancy between the simulation model and actual operation. Interval errors between the simulated results of the calibrated model were typically within $\pm 15 \%$. Therefore, the calibrated model was deemed acceptable for evaluating the impact of various pre-cooling and temperature reset strategies.

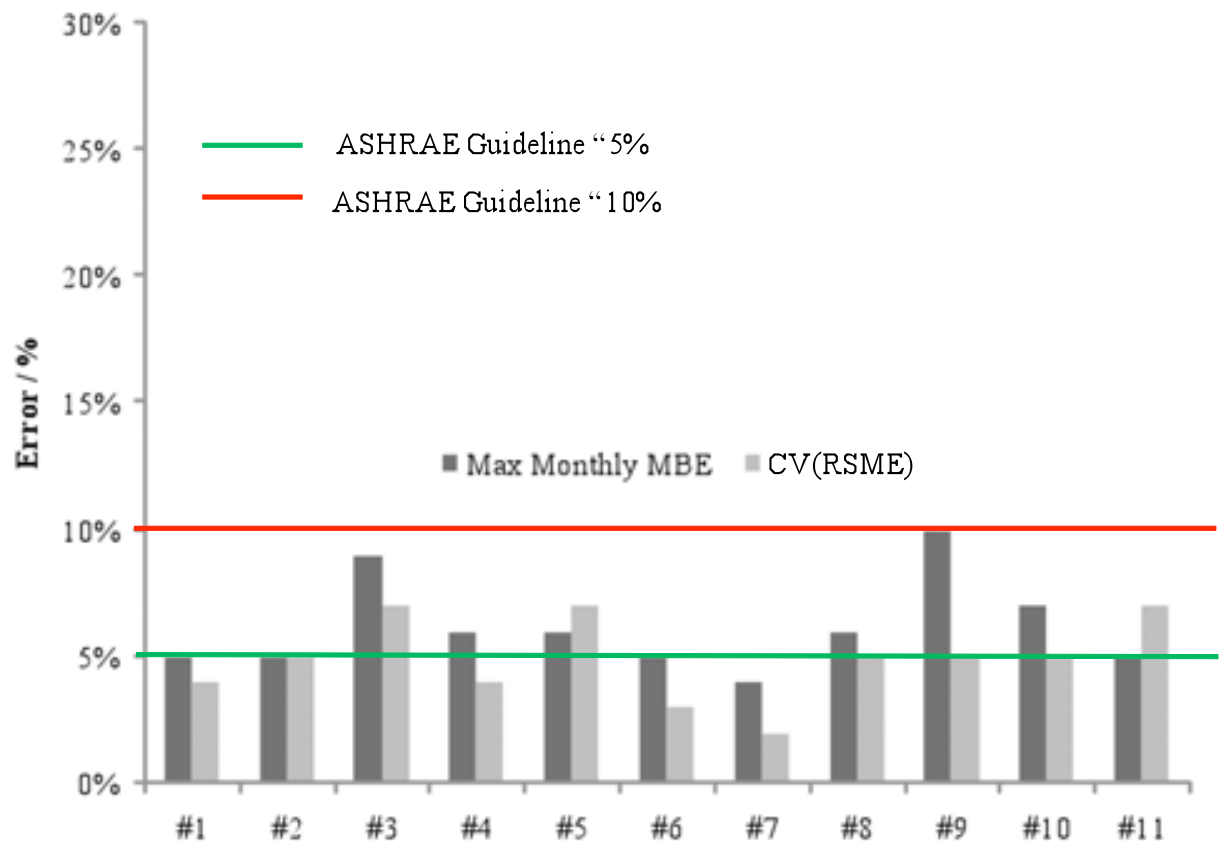

Figure 7 Difference of Monthly Electric Usage between Calibrated Model and Measured Data for Field Test Buildings 


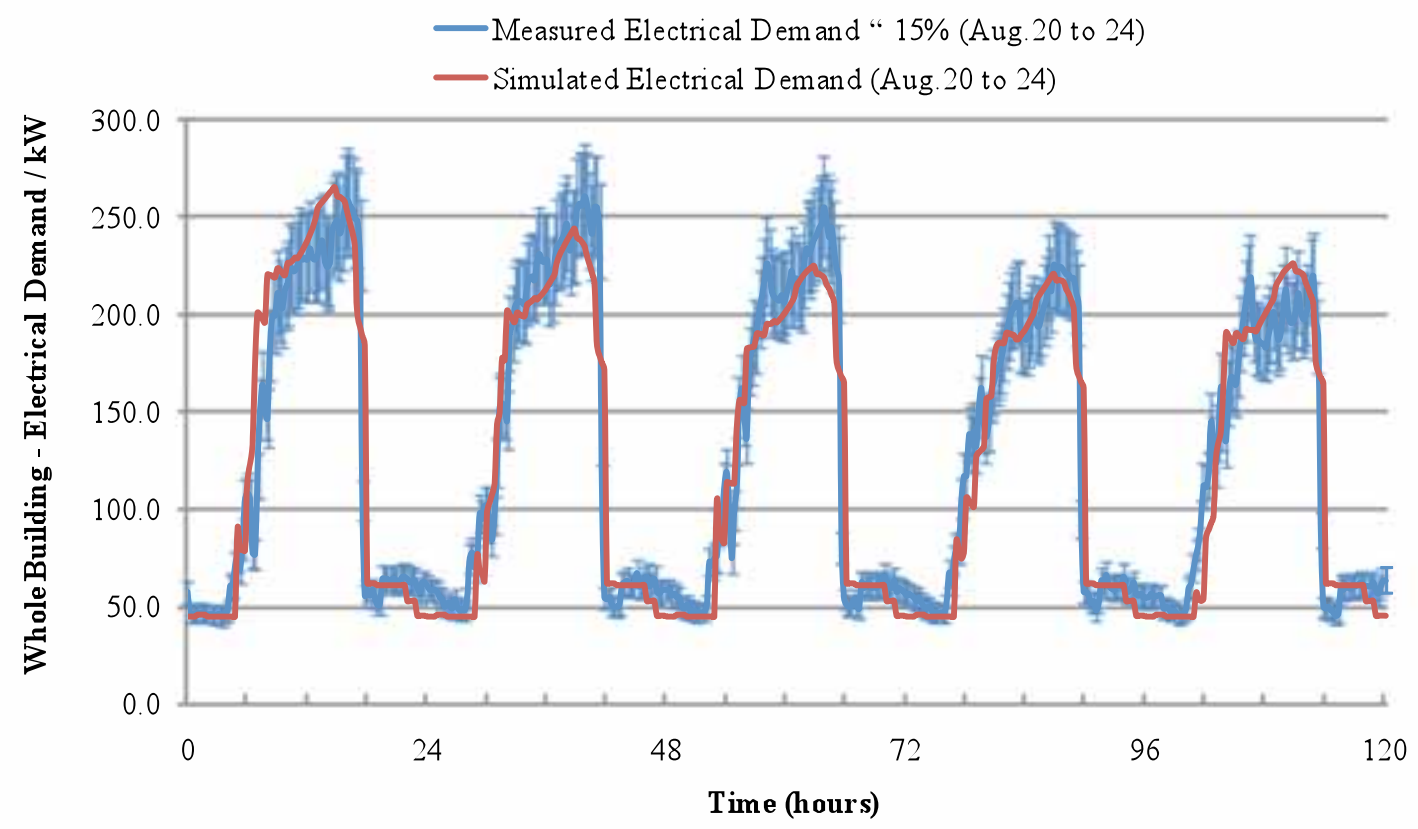

Figure 8 Comparison of Electrical Demand between Calibrated Model and Measured Data

\subsection{Optimization of Pre-cooling Strategies}

Calibrated models were used to investigate and analyze various pre-cooling strategies. The pre-cooling and zone temperature reset strategies that have been examined in this study are shown in Figure 9. According to the trended operation data, each of these buildings were normally operated at constant setpoints around $25^{\circ} \mathrm{C}\left(77^{\circ} \mathrm{F}\right)$ throughout the warm-up and occupied hours. After $6 \mathrm{pm}$, the system was shut off and zone temperatures started to float. The setpoints in individual zones ranged from $23.9^{\circ} \mathrm{C}$ $\left(75^{\circ} \mathrm{F}\right)$ to $26.7^{\circ} \mathrm{C}\left(80^{\circ} \mathrm{F}\right)$, with an average value of about $25^{\circ} \mathrm{C}\left(77^{\circ} \mathrm{F}\right)$.

The first strategy was termed as "pre-cooling with linear temp reset". From 5 am to $12 \mathrm{pm}$, mostly during occupied hours, all of the zone temperature setpoints were reduced to $23.9^{\circ} \mathrm{C}\left(75^{\circ} \mathrm{F}\right)$. From $12 \mathrm{pm}$ to $6 \mathrm{pm}$, the high price periods, the setpoints were raised linearly to $26.7^{\circ} \mathrm{C}\left(80^{\circ} \mathrm{F}\right)$. After $6 \mathrm{pm}$, before the system was shut off, the setpoints were rolled back to $25^{\circ} \mathrm{C}\left(77^{\circ} \mathrm{F}\right)$.

The second strategy was termed as "pre-cooling with exponential temp reset". While the pre-cooling period was same as the first strategy, the temperatures were raised up exponentially rather than linearly in the afternoon period.

The third strategy was called "no pre-cooling with exponential temp reset". The zone temperatures were raised exponentially in the afternoon in the same way as in the last strategy, but without pre-cooling from 5 am to $12 \mathrm{pm}$. One aim of the tests was to determine the effect of the pre-cooling on peak demand shedding.

The fourth strategy was called "pre-cooling with step temp reset". The zone temperature setpoints were reduced to $23.9^{\circ} \mathrm{C}\left(75^{\circ} \mathrm{F}\right)$ from 5 am to $12 \mathrm{pm}$. The setpoints were raised to $26.1^{\circ} \mathrm{C}\left(79^{\circ} \mathrm{F}\right)$ at $12 \mathrm{pm}$ and remained there until $3 \mathrm{pm}$. At $3 \mathrm{pm}$, the zone temperature setpoints were reset at $26.7^{\circ} \mathrm{C}\left(80^{\circ} \mathrm{F}\right)$ and remained there for the duration of the afternoon. 


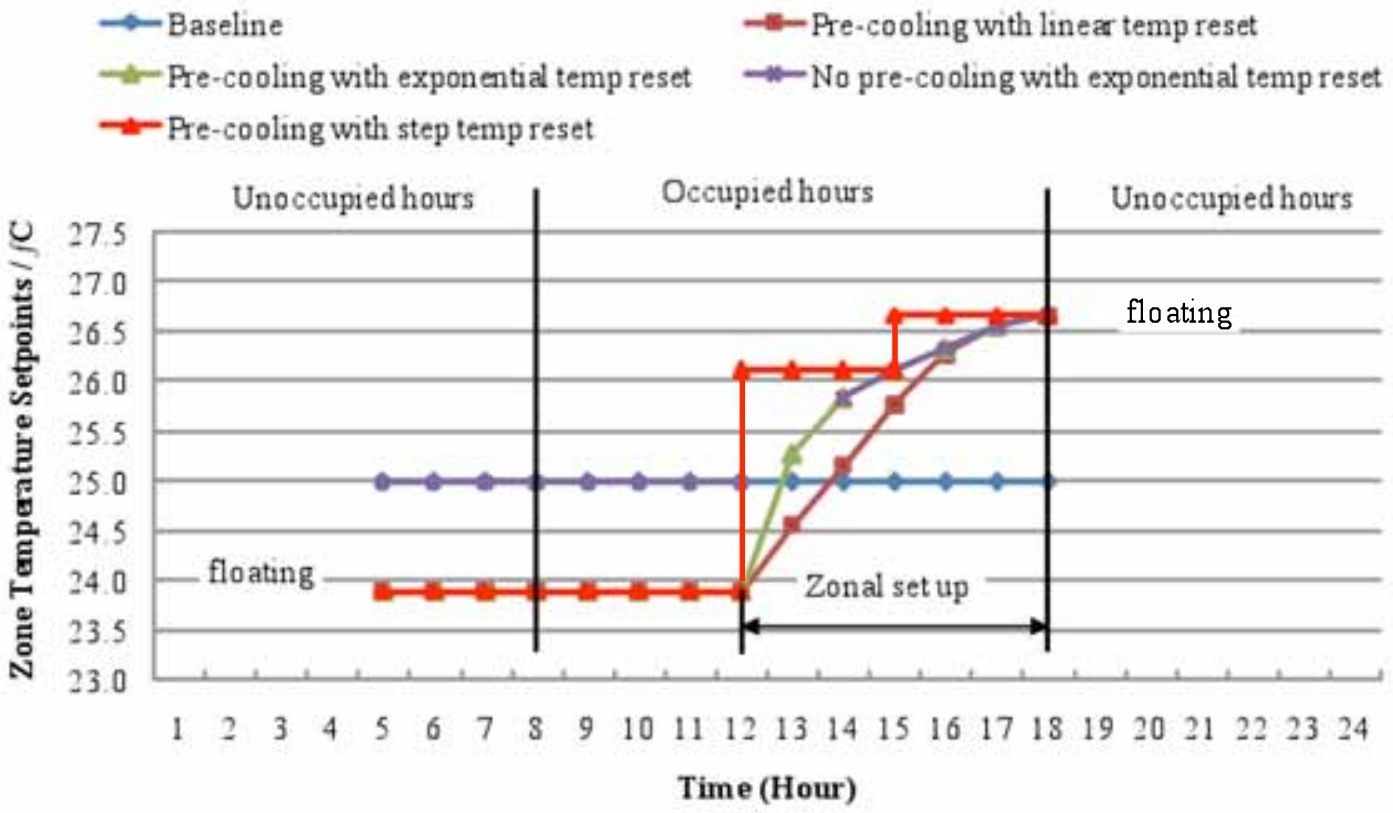

Figure 9 Pre-cooling and Zonal Temperature Reset Strategies

A series of simulations for each of the four pre-cooling strategies was conducted for each building. Simulation results were compared with measured data. Figure 10 shows the simulation results for one office building. The plot illustrates the demand shed for different types of pre-cooling strategies during the high price period. The "Pre-cooling with step temp set up" strategy load profile was much flatter than others, and the "Pre-cooling with exponential temp set up" strategy load profile was also better than the "No pre-cooling with exponential temp set up" and "Pre-cooling with linear temp set up" strategies' load profiles. The "Pre-cooling with step temp set up" strategy could discharge the thermal mass more smoothly and create a flat power profile during the peak period. The "Pre-cooling with linear temp set up" strategy load profile fluctuated throughout the temperature reset period and the shed was smaller than that of "exponential set up" and "step set up" strategies. 


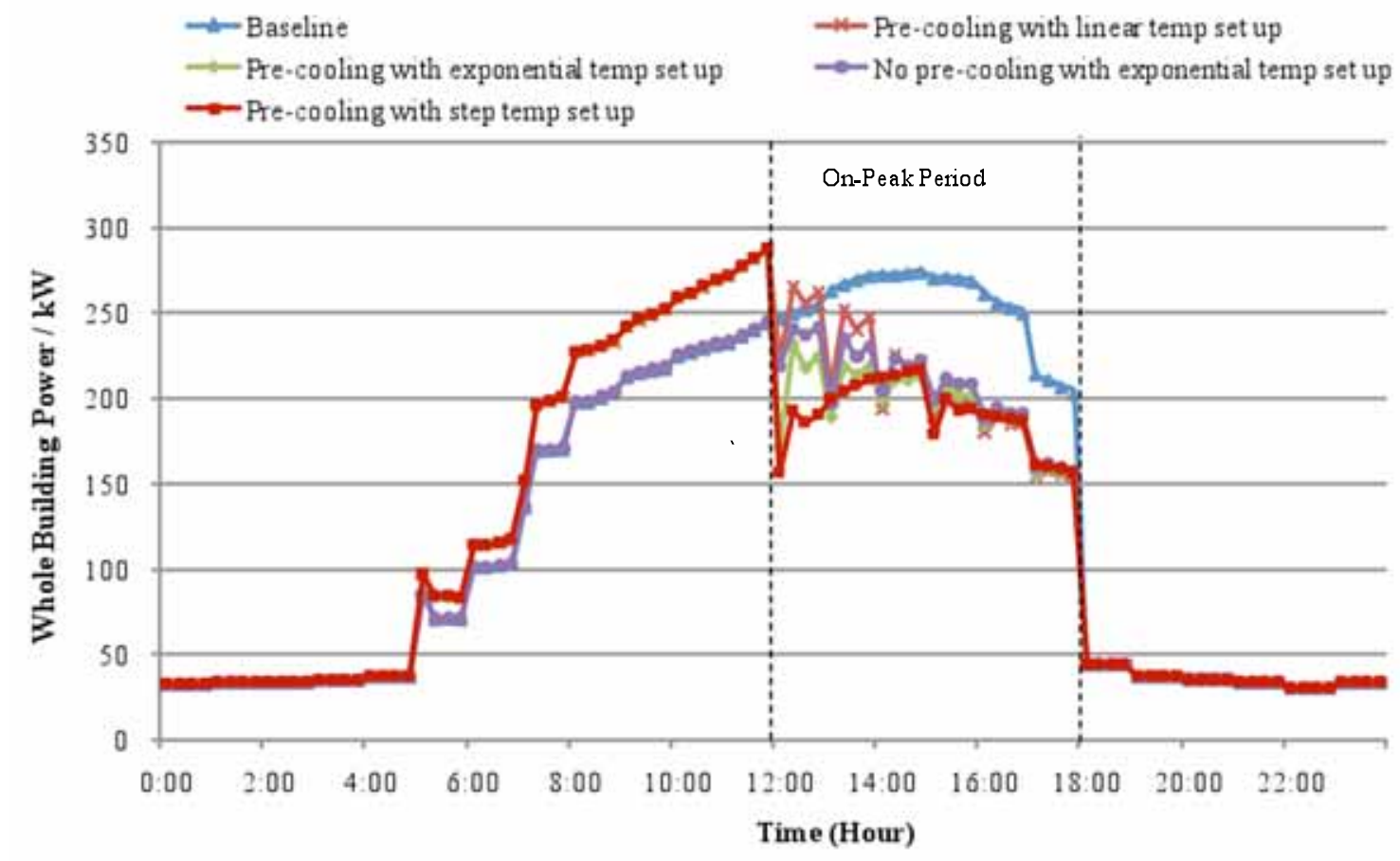

Figure 10 Simulation Results of Proposed Pre-cooling Strategies

\section{Pre-cooling Field Test Analysis}

In summer 2008, the optimal pre-cooling strategy was implemented in each building using a signal initiated by the automated demand response (Auto-DR) system, which eliminates the need for human intervention in each field test building. Auto-DR can be defined as fully-automated DR initiated by a signal from a utility or other appropriate entity that provides fully-automated connectivity to customer end-use control strategies [22, 23]. It allows greater levels of participation and improved reliability and repeatability of the demand response and customer facilities [24]. A recently published specification describes an open standards - based communications data model designed to promote common information exchange between the utility or Independent System Operator and electric customers using demand response price and reliability signals [25]. In this study, field tests of optimal pre-cooling strategies using the Auto-DR system were conducted on all twelve DR events from July to September. Figure 11 shows the pre-cooling strategy used on the Auto-DR event days for each of the buildings. 


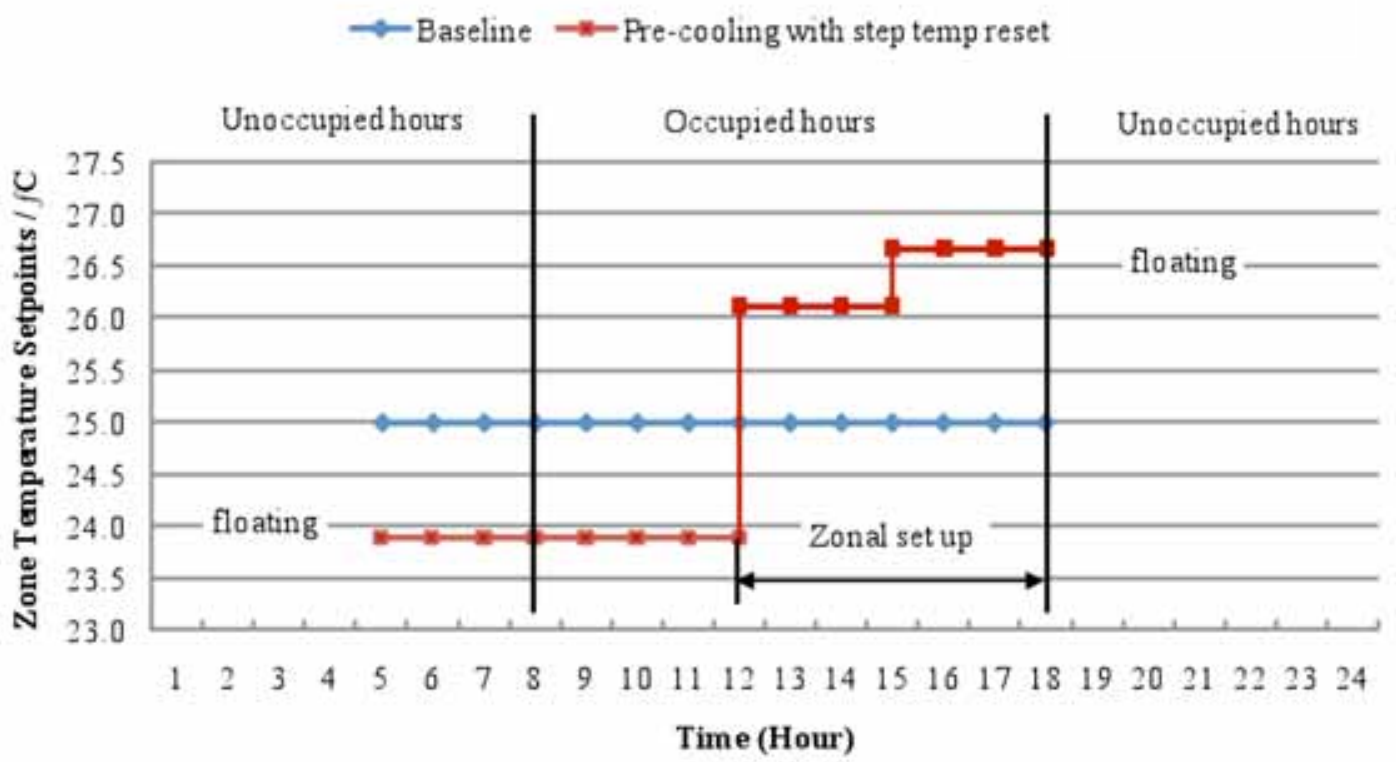

Figure 11 Pre-cooling Strategies on Auto-DR Test Days

\subsection{Baseline Model Confirmation}

In the 2003 and 2004 studies, a strong correlation between maximum outside air temperature and whole building peak power was observed [4]. In order to minimize the weather difference between simulations and test days, baseline days for each test day were selected based on similarity of peak outside air temperatures, and profiles of the outside temperatures.

Simply comparing maximum outside air temperature was not a reliable method to select baselines. The average variance of hourly outside air temperatures (AVHOAT) between the baseline days and test days provides an additional metric defined as:

$$
\text { AVHOAT }=\frac{1}{24} \sum_{i=1}^{24}\left(B_{i}-T_{i}\right)^{2}
$$

Where $B_{i}$ is the hourly outside air temperature of baseline days and $T_{i}$ is the hourly outside air temperature of Auto-DR test days.

Table 4 presents five potential baseline days that had similar maximum outside air temperature to that of the 9/3/2008 test day. By only comparing the Peak OA Temperature, any of these five baseline days could be considered to be the best baseline day. The AVHOAT method, however, shows that 9/4/2008 had the smallest AVHOAT and the hourly outside air temperature on baseline days were almost the same as that on the Auto-DR event day - thus 9/4/2008 would be the best match to use for the baseline day. This same AVHOAT method was used to select the best baseline days for the other test event days.

Table 4 OA Temperature Comparison between Baseline Days and Auto-DR Test Days

\begin{tabular}{lcccccc}
\hline Index & Test Day & \multicolumn{5}{c}{ Baseline Days } \\
\hline Date & $9 / 3 / 08$ & $9 / 2 / 08$ & $9 / 4 / 08$ & $9 / 5 / 08$ & $9 / 15 / 08$ & $9 / 25 / 08$ \\
\hline Peak OA temperature $\left({ }^{\circ} \mathrm{C}\right)$ & 36.7 & 37.2 & 36.1 & 37.8 & 37.2 & 36.7 \\
\hline AVHOAT $\left({ }^{\circ} \mathrm{C}\right)$ & - & 1.65 & 0.53 & 0.55 & 2.42 & 1.50 \\
\hline
\end{tabular}

LBNL developed a baseline model to estimate the demand savings from implementing the DR strategies. Previous research recommended a weather-sensitive baseline model with adjustments for 
morning load variations. With respect to the LBNL baseline model, the whole building power baseline was estimated using a regression model that assumes that whole building power was linearly correlated with outside air temperature (OAT) [26]. Each of these two baselines were applied to evaluate the effect of demand response strategies for decreasing the peak demand.

In general, the baseline models for each Auto-DR event day were achieved based on similarity of the peak and hourly outside air temperature between the baseline days and the Auto-DR event days and with the assumption of similar internal operating loads such as lighting and plug loads. However, some buildings were not very sensitive to outside weather conditions; rather, lighting and plug loads account for the majority of electricity usage - these loads significantly influenced the whole building power profile. Under this condition, a combination of end-use submetering and weather condition sensitivity analysis was recommended to find suitable baseline days for each Auto-DR event day.

\subsection{Field Test Results}

Figure 12 shows the whole building power for the 9/3/2008 Auto-DR event days as well as the corresponding 9/4/2008 baselines from the (AVHOAT) and LBNL baseline models. As shown in Figure 12 , there was little difference between these two baseline models due to the high similarity between the selected baseline day and the Auto-DR day.

Building site \# 8, 9/3/2008 (Max OAT: $36.7 f$ C)

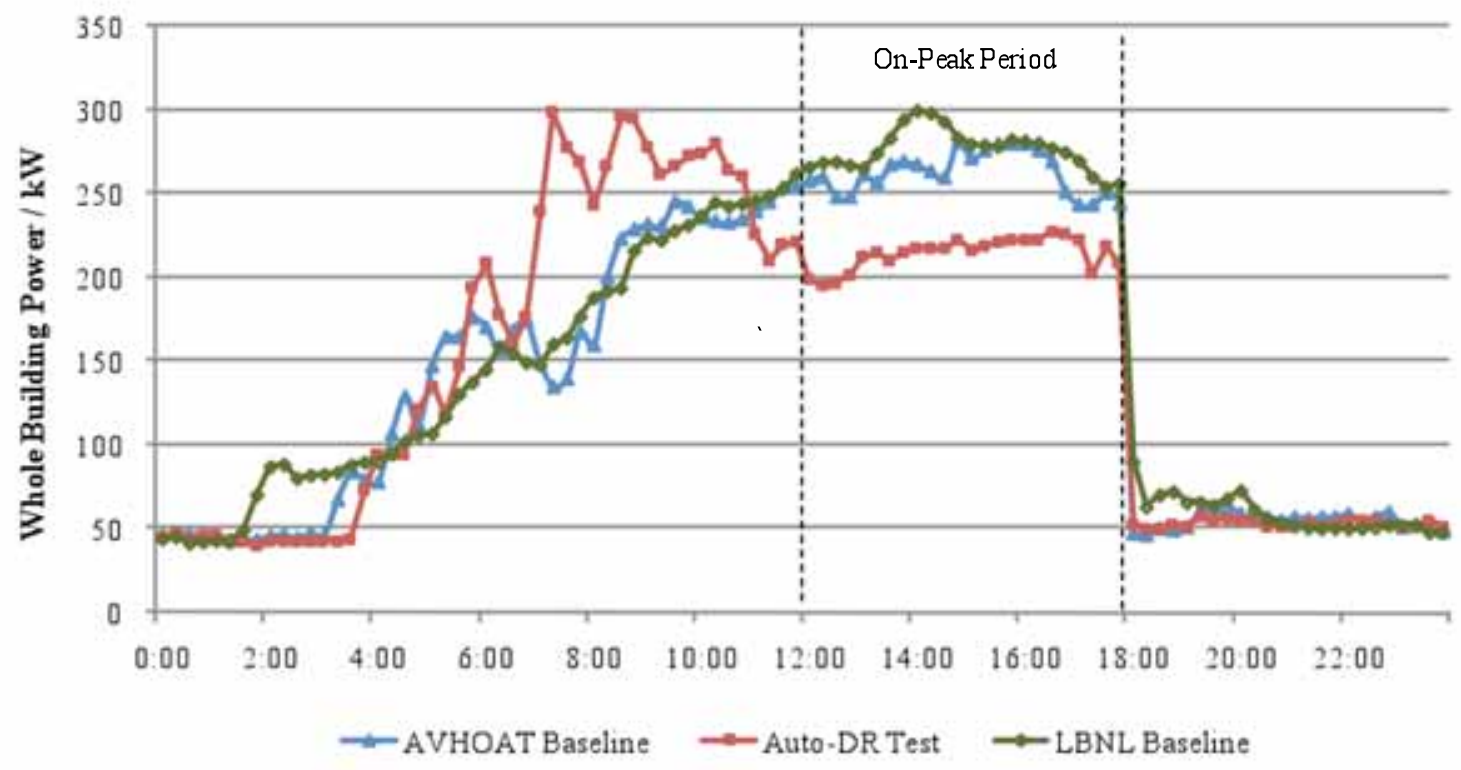

Figure 12 Field Test Results of Pre-cooling Strategies on One Auto-DR Test Day

The field test results in Figure 12 show significant peak demand savings for the "Pre-cooling with step set up" strategy throughout the Auto-DR event days in the office building (\#8). Note that the load shifted from the afternoon peak period to the morning off-peak period (pre-cooling period). By operating the optimal pre-cooling strategy as shown in Figure 11, the average peak demand saving was about $18 \%$ of the whole facility load based on the six-hour peak period, and the peak demand was reduced by as much as $23 \%$. Meanwhile, the demand curve during the peak period was controlled at a nearly constant value; no rebounds were observed for the electrical demand of the HVAC system. The trend data indicated that the temperature had not reached the $26.7^{\circ} \mathrm{C}\left(80^{\circ} \mathrm{F}\right)$ setpoint at the end of the HVAC system operation, due to the discharged cooling energy from building thermal mass. If the thermal mass had been fully 
discharged during the peak period, the HVAC system would have had to provide more cooling to keep the building at the setpoints - thus resulting in higher demand. As this building had sufficient thermal mass to carry the building at the experimental setpoints, the peak period zone temperature setpoints could have been reset higher to take full advantage of the building's thermal mass.

\subsection{Comparison of Measured Data and Simulation Predictions}

Figure 13 compares the measured data to the simulation results. Depending on the test day, the average demand shift predicted by the simulation models was slightly higher or lower than the measured data. Among the DRQAT inputs, level of thermal mass had the largest impact on peak demand reductions. The building thermal mass level was set to "Medium" in the first calibrated models, which was confirmed according to the characteristics of typical office buildings [17]. The survey data did not provide enough information to quantify thermal mass. The thermal mass level was generally reset to match actual conditions in the individual buildings based on the building's structure survey data. In the future, the building thermal capacity can be estimated by several models developed by J.E. Braun and k-H Lee [6, 27, 28] through short-term measurement and field surveys.

In Figure 13, during the peak period, with the exception of buildings \#4 and \#6, simulated demand savings agree well with those of the measured data. To determine the cause for inconsistency in office building \#4's results, a detailed analysis of the actual whole building electric load profile was conducted for the Auto-DR test days. By comparing the on Auto-DR test days' whole building power profiles with the baseline days' profiles, the results in Figure 14indicated that the pre-cooling with zone temperature reset strategy did not work on the Auto-DR test days, as there were some implementation problems. There was no trend to achieve demand shed when Auto-DR signal was activated. It was verified that this building didn't participated in the Auto-DR program during the summer 2008. Office building \#6's measured average demand savings were higher than those of the simulation model. This discrepancy may have been due to the chiller staging control with the operation of zone temperature reset during the peak period. As shown in Figure 15, the whole building power profile fluctuated throughout the peak period, while the simulated power profile during the peak hours was flat. Though significant average demand savings were achieved, the peak demand was even higher than normal operation without the demand response strategy.

The optimal pre-cooling strategy worked well in the other office buildings and was able to reduce the peak electric demand significantly. As shown in Figure 12, the whole building power (WBP) profiles on the Auto-DR test days indicted no rebound in the afternoon. Table 5 presents a summary of measured and simulated demand savings for all eleven test buildings - the electrical demand during the peak period was reduced by $15 \sim 30 \%$ on the Auto-DR event days. The pre-cooling with zone temperature step reset strategy was successful in decreasing the peak demand of the whole building, thus providing significant energy cost savings. The comparison results indicate that the calibrated models can be used to predict the demand savings from other demand response strategies. 


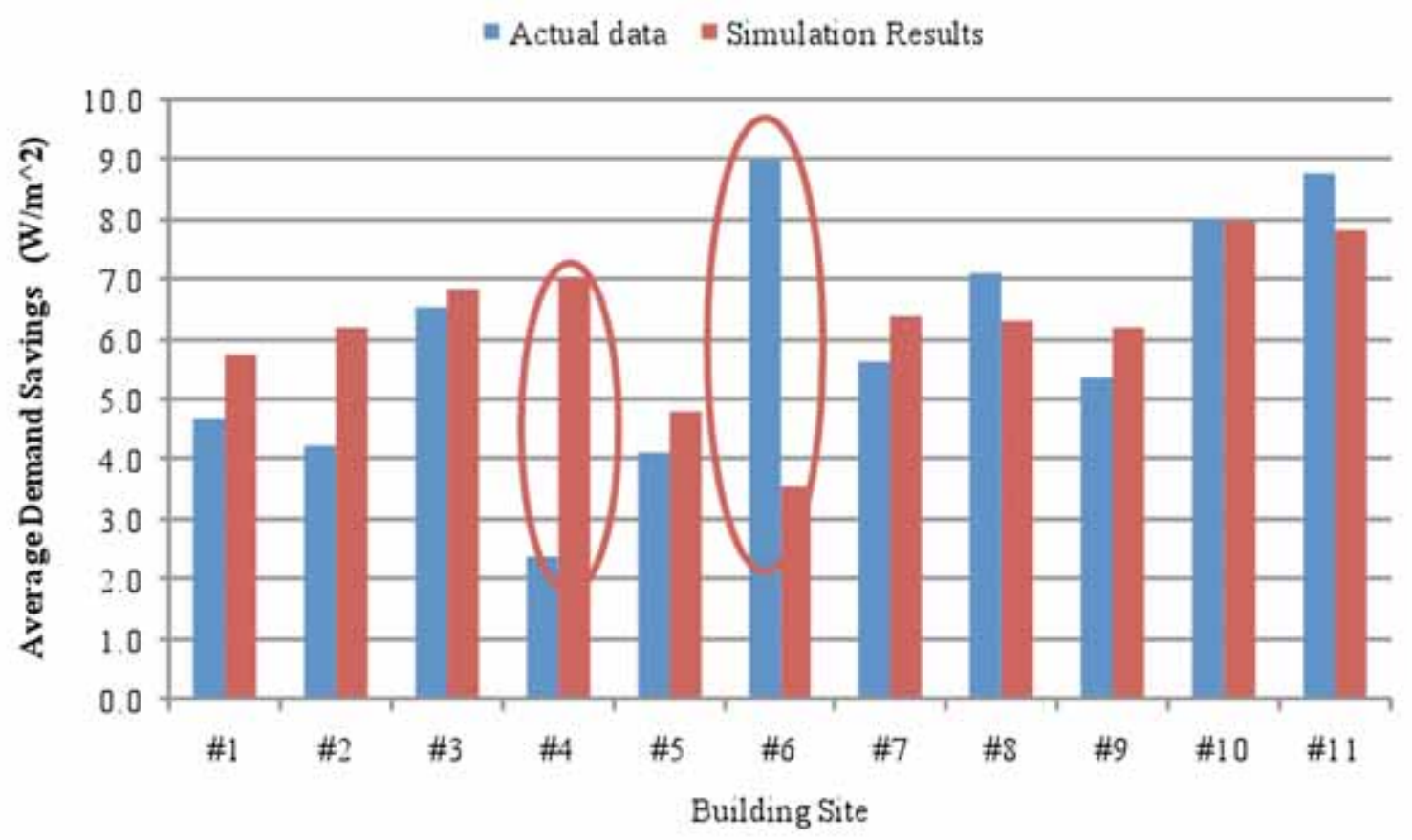

Figure 13 Comparison of Measured and Simulated Average Demand Savings for Field Test Buildings

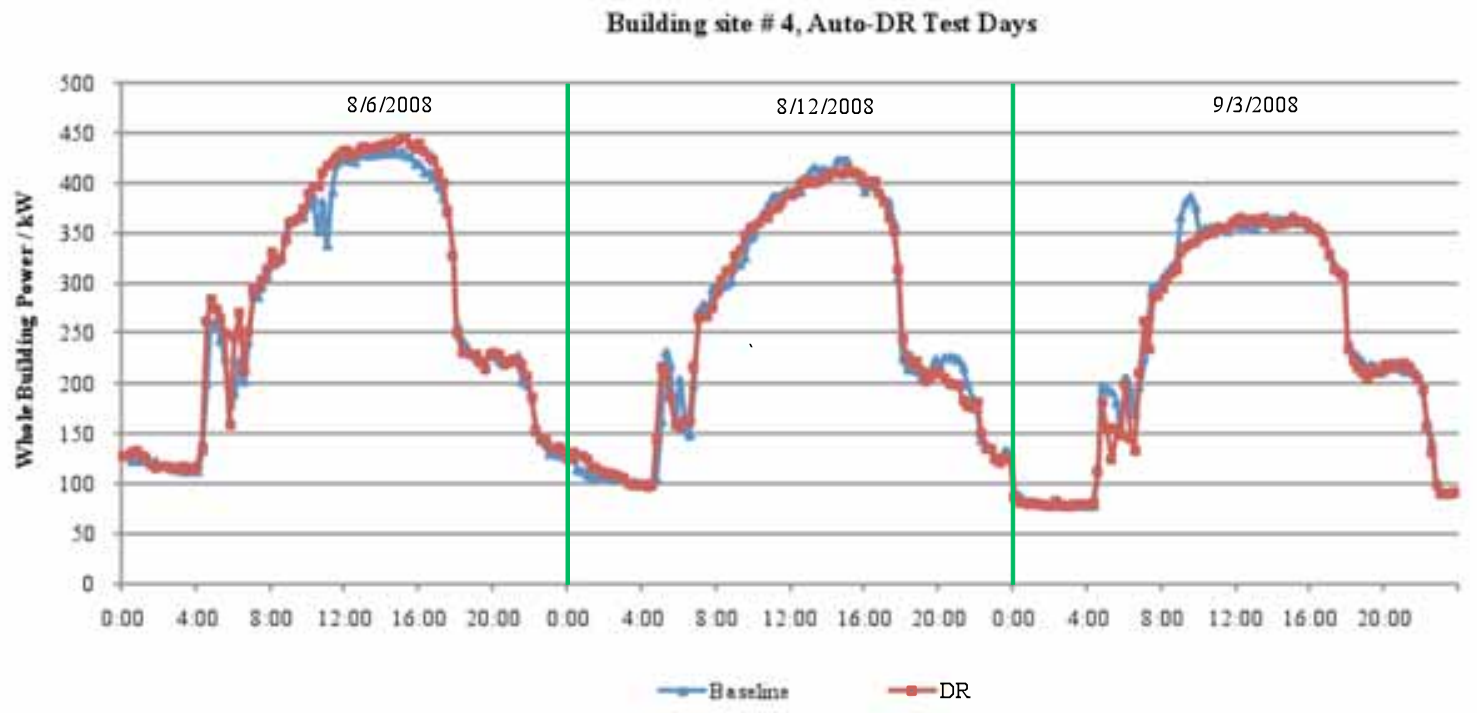

Figure 14 Comparison of the Three Auto-DR Test days' Whole Building Power Profiles and the Baseline's Profiles 
Building site \#6, 8/12/2008 (Max OAT: $35 f C$ )

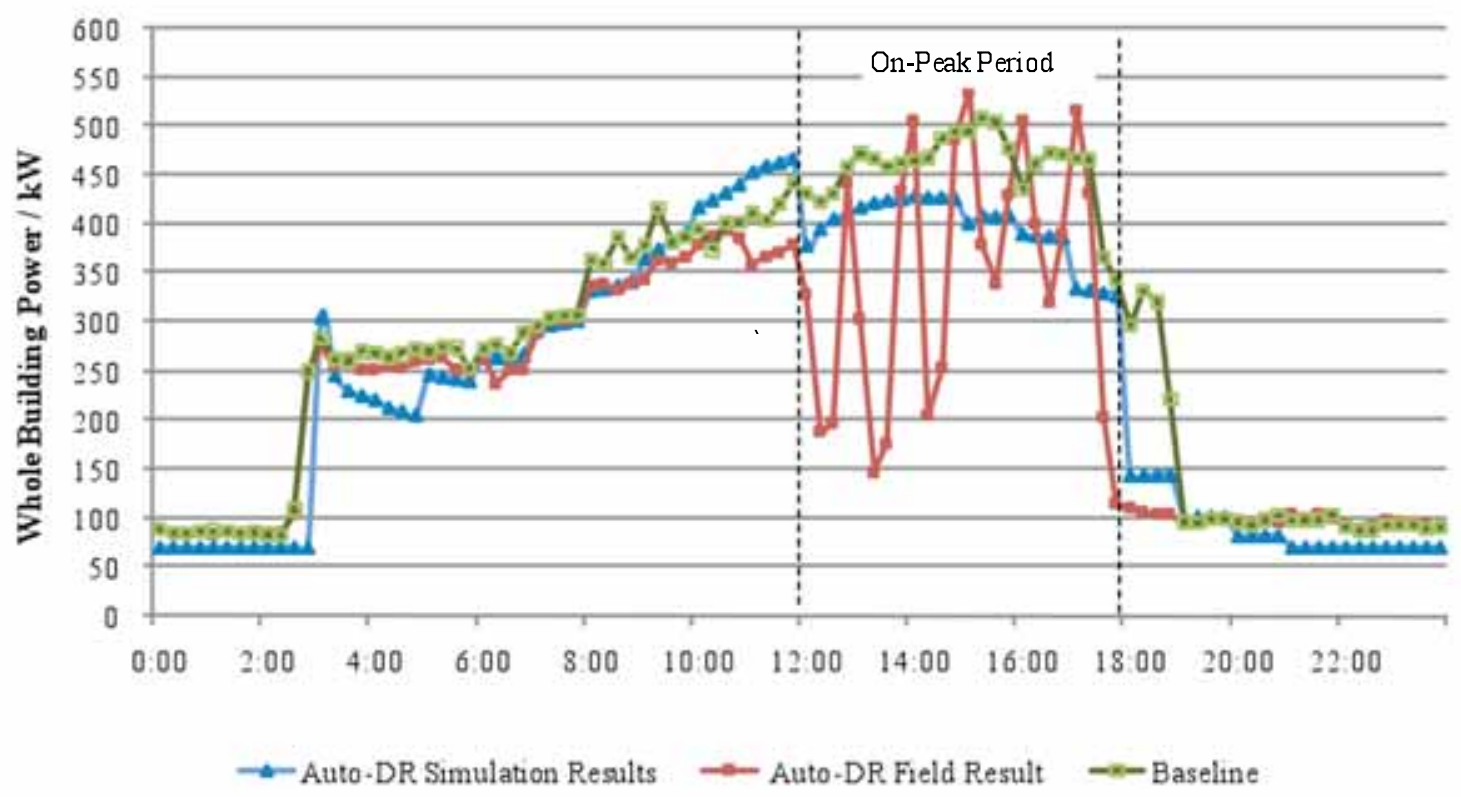

Figure 15 Discrepancy between Measured and Simulated Demand Savings in Site \#6

Table 5 Summary of Measured and Simulated Demand Savings for Field Test Buildings

\begin{tabular}{|c|c|c|c|c|c|c|c|}
\hline \multirow{2}{*}{ Site No. } & \multirow{2}{*}{ Demand Savings } & \multicolumn{2}{|c|}{$\mathrm{kW}$} & \multicolumn{2}{|c|}{$\mathrm{W} / \mathrm{m}^{2}$} & \multicolumn{2}{|c|}{ WBP\% } \\
\hline & & Max & Ave & Max & Ave & Max & Ave \\
\hline \multirow{2}{*}{ \#1 } & Measured & 43.5 & 30.0 & 6.8 & 4.7 & $17 \%$ & $12 \%$ \\
\hline & Simulated & 62.2 & 36.7 & 9.7 & 5.7 & $23 \%$ & $13 \%$ \\
\hline \multirow{2}{*}{ \#2 } & Measured & 61.9 & 24.6 & 10.6 & 4.2 & $17 \%$ & $7 \%$ \\
\hline & Simulated & 64.8 & 36.1 & 11.1 & 6.2 & $20 \%$ & $11 \%$ \\
\hline \multirow{2}{*}{ \#3 } & Measured & 63.5 & 23.5 & 8.2 & 3.0 & $30 \%$ & $11 \%$ \\
\hline & Simulated & 54.1 & 24.6 & 15.1 & 6.8 & $24 \%$ & $11 \%$ \\
\hline \multirow{2}{*}{ \#4 } & Measured & 31.0 & 16.4 & 4.0 & 2.2 & $7 \%$ & $4 \%$ \\
\hline & Simulated & 100.3 & 48.0 & 14.6 & 7.0 & $22 \%$ & $10 \%$ \\
\hline \multirow{2}{*}{ \#5 } & Measured & 56.9 & 26.8 & 7.3 & 3.5 & $17 \%$ & $8 \%$ \\
\hline & Simulated & 62.6 & 31.2 & 9.6 & 4.8 & $16 \%$ & $8 \%$ \\
\hline \multirow{2}{*}{ \#6 } & Measured & 234.2 & 94.2 & 30.1 & 12.2 & $46 \%$ & $18 \%$ \\
\hline & Simulated & 77.5 & 37.1 & 7.4 & 3.6 & $13 \%$ & $6 \%$ \\
\hline \multirow{2}{*}{ \#7 } & Measured & 101.0 & 42.1 & 13.0 & 5.4 & $26 \%$ & $11 \%$ \\
\hline & Simulated & 85.4 & 47.8 & 11.4 & 6.4 & $23 \%$ & $13 \%$ \\
\hline \multirow{2}{*}{ \#8 } & Measured & 74.4 & 55.1 & 9.6 & 7.1 & $27 \%$ & $20 \%$ \\
\hline & Simulated & 80.7 & 48.9 & 10.4 & 6.2 & $26 \%$ & $16 \%$ \\
\hline \#9 & Measured & 74.5 & 51.9 & 9.6 & 6.7 & $16 \%$ & $11 \%$ \\
\hline
\end{tabular}




\begin{tabular}{llllllll}
\hline & Simulated & 105.5 & 60.2 & 10.9 & 6.2 & $23 \%$ & $13 \%$ \\
\hline \multirow{2}{*}{$\# 10$} & Measured & 130.1 & 88.6 & 16.7 & 11.4 & $27 \%$ & $18 \%$ \\
\cline { 2 - 7 } & Simulated & 139.7 & 88.2 & 12.6 & 8.0 & $31 \%$ & $20 \%$ \\
\hline \multirow{2}{*}{$\# 11$} & Measured & 115.5 & 66.1 & 14.9 & 8.5 & $25 \%$ & $14 \%$ \\
\cline { 2 - 8 } & Simulated & 90.1 & 58.8 & 12.0 & 7.8 & $25 \%$ & $16 \%$ \\
\hline
\end{tabular}

\section{Guidelines to Develop and Calibrate DRQAT Model}

Through this study, this experience with simulation-based DR optimization was summarized in a procedure to develop and calibrate DRQAT building models with the following steps:

- Generate a DRQAT initial simulation model with basic building information;

- Replace TMY weather file in DRQAT and regenerate an EPW EnergyPlus file with real weather data collected from the site or the nearby weather stations;

- Use whole building power under extreme cold weather conditions to estimate the actual lighting and equipment end use load profiles. The method will not work if electricity or heat pumps were used as heating sources;

- Run simulations and compare the simulated results with the measured data;

- Readjust the internal load schedule until the simulated monthly and hourly demand data match with the measured data.

\section{Conclusions and Recommendations for Future Work}

This paper evaluated how to optimize and verify pre-cooling strategies for office buildings in a hot climate zone with the assistance of the Demand Response Quick Assessment Tool (DRQAT) - a building energy simulation tool. The simulation results from calibrated simulation models matched well with the actual monthly and hourly data. Using the calibrated simulation models, a series of simulations were conducted to determine optimal pre-cooling strategies for the eleven buildings. "Pre-cooling with exponential temp set up" and "Pre-cooling with step temp set up" strategies turned out to be better DR strategies compared to the "Pre-cooling with linear temp set up" strategy.

The field test results indicated that the pre-cooling strategies were able to reduce the peak demand as expected on Auto-DR event days. For all test buildings, the electrical demand during the peak period was reduced by $15 \sim 30 \%$ on the Auto-DR event days.

The demand shed predicted by DRQAT matched well with the measured data on Auto-DR event days. The study showed that after refining and calibrating the initial simulation models based on measured data, the accuracy of the models was greatly improved and the models could be used to reliably predict load reductions in most of buildings on DR event days within $\pm 10 \%$. Although agreement was found between the carefully calibrated baseline model and the measured interval meter data, efforts in the following areas can further improve the accuracy of the simulations and usefulness of the DRQAT tool: measured or real weather data, sub-metered HVAC and whole building power, and better estimation of building internal mass. This study confirms that sub-metered HVAC and whole building power data were crucial to the accuracy of the models. If this data is not available, the auditor may conduct a manual test on a weekend to measure end use consumption and demand indirectly. It was difficult to assess the building's thermal mass level. It would be useful to conduct short-term measurements and field investigations to determine the capacity of the building's thermal mass and incorporate these mass models [6, 29] into the simulation model.

\section{Acknowledgements}


This work described in this paper was coordinated by the Demand Response Research Center and was funded by Southern California Edison (SCE), under contract No. DR 08-02, the California Energy Commission (Energy Commission) Public Interest Energy Research (PIER) Program under Work for Others Contract No. 500-03-026 and by the U.S. Department of Energy under Contract No. DE-AC02-05CH11231. The authors are grateful for the extensive support from SCE, Global Energy Partners (GEP), and the Auto-DR program managed by LBNL. Special thanks to our project managers, J. Carlos Haiad (SCE) and Kristy Chew (California Energy Commission). Thanks also to Joe Prijyanonda from Global Energy Partners (GEP) for technical support.

\section{References}

[1] A. Rabl and L. K. Norford, Peak load reduction by preconditioning buildings at night, International Journal of Energy Research 15 (1991), pp. 781-798.

[2] F. B. Morris, J. E. Braun, and S. J. Treado, Experimental and simulated performance of optimal control of building thermal storage, ASHARE Transactions 100 (1994), pp. 402-414.

[3] K. R. Keeney and J. E. Braun, Application of building precooling to reduce peak cooling requirements, ASHRAE Transactions 103 (1997), pp. 463-469.

[4] P. Xu, P. Haves, J. E. Braun, and L. t. Hope, Peak demand reduction from pre-cooling with zone temperature reset in an office building, in Proceedings of 2004 ACEEE Summer Study of Energy Efficiency in Buildings, Pacific Grove, CA, 2004.

[5] P. Xu and P. Haves, Case study of demand shifting with thermal mass in two large commercial buildings, ASHARE Transactions 112 (2005), pp. 875-888.

[6] J. E. Braun, Load Control Using Building Thermal Mass, Journal of Solar Energy Engineering 125 (2003), pp. 292-301.

[7] N. Motegi, M. A. Piette, D. S. Watson, S. Kiliccote, and P. Xu, Introduction to commercial building control strategies and techniques for demand response, Lawrence Berkeley National Laboratory, Berkeley, LBL-59975, 2007.

[8] Y. J. Huang, H. Akbari, L. Rainer, and R. Ritschard, 481 prototypical commercial buildings for 20 urban market areas, Lawrence Berkeley National Laboratory, Berkeley, LBL-29278, 1991.

[9] P. Xu, P. Haves, M. A. Piette, and L. Zagreus, Demand shifting with thermal mass in large commercial buildings: field tests, simulations and audits, Lawrence Berkeley National Laboratory, LBNL-58815, 2005.

[10] ASHRAE Guideline 14, Measurement of Energy and Demand Savings, ASHRAE Standards Committee, 2002.

[11] J. Yoon, E. J. Lee, and D. F. Claridge, Calibration procedure for energy performance simulation of a commercial building, Journal of Solar Energy Engineering 125 (2003), pp. 251-257.

[12] T. A. Reddy, M. Itzhak, and C. Panjapornpon, Calibrating detailed building energy simulation programs with measured data - Part I: general methodology, HVAC\&R Research Journal 13 (2007),

[13] T. A. Reddy, M. Itzhak, and C. Panjapornpon, Calibrating detailed building energy simulation programs with measured data - Part II: application to three case study office buildings, $H V A C \& R$ Research Journal 13 (2007),

[14] Y. Pan, Z. Huang, and G. Wu, Calibrated building energy simulation and its application in a high-rise commercial building in Shanghai, Energy and Buildings 39 (2007), pp. 651-657.

[15] L. K. Norford, R. H. Socolow, E. S. Hsieh, and G. V. Spadaro, Two-to-one discrepancy between measured and predicted performance of a 'low-energy' office building: insights from a reconciliation based on the DOE-2 model, Energy and Buildings 21 (1994), pp. 121-131.

[16] 2005 Building Energy Efficiency Standards for Residential and Non Residential Buildings, California Energy Commission, 2005. 
[17] P. Torcellini, M. Deru, B. Griffith, K. Benne, M. Halverson, D. Winiarski, and D. B. Crawley, DOE Commercial Building Benchmark Models, in Proceeding of 2008 ACEEE Summer Study on Energy Efficiency in Buildings, Pacific Grove, California, August 17-22, 2008.

[18] J. S. Haberl and S. Thamilseran, Predicting hourly building energy use: the great energy predictor shootout II: measuring retrofit savings, ASHRAE Journal 40 (1998), pp. 49-56.

[19] J. F. Kreider and J. S. Haberl, Predicting hourly building energy usage: the great energy predictor shootout: overview and discussion of results, ASHARE Transactions 100 (1994), pp. 1104-1118.

[20] J. F. Kreider and J. S. Haberl, Predicting hourly building energy usage: the results of the 1993 great energy predictor shootout identify the most accurate method for making hourly energy use predictions, ASHARE Journal 36 (1994), pp. 72-81.

[21] M\&V Guidelines: Measurement and Verification for Federal Energy Projects Version 3.0, U.S. Department of Energy, Federal Energy Management Program, 2008.

[22] S. Kiliccote, M. A. Piette, G. Wikler, J. Prijyanonda, and A. Chiu, Design and Implementation of an Open, Interoperable Automated Demand Response Infrastructure, in 16th National Conference on Building Commissioning, Newport Beach, CA, April 22-24, 2008.

[23] M. A. Piette, O. Sezgen, D. S. Watson, N. Motegi, and C. Shockman, Development and Evaluation of Fully Automated Demand Response in Large Facilities, Lawrence Berkeley National Laboratory CEC-500-2005-013, Berkeley, LBNL-55085, 2005.

[24] M. A. Piette, S. Kiliccote, and G. Ghatikar, Design and Implementation of an Open, Interoperable Automated Demand Response Infrastructure, Lawrence Berkeley National Laboratory, Berkeley, LBNL-63665, 2007.

[25] M. A. Piette, G. Ghatikar, S. Kiliccote, E. Koch, D. Hennage, P. Palensky, and C. McParland, Open Automated Demand Response Communications Specification (Version 1.0), California Energy Commission, PIER Program. CEC-500-2009-0632009, 2009.

[26] K. Coughlin, M. A. Piette, C. Goldman, and S. Kiliccote, Estimating Demand Response Load Impacts: evaluation of baseline load models for non-residential buildings in California, Lawrence Berkeley National Laboratory, LBNL-63728, 2008.

[27] K.-H. Lee and J. E. Braun, Development of methods for determining demand-limiting setpoint trajectories in buildings using short-term measurements, Building and Environment 43 (2008), pp. $1755-1768$.

[28] K.-H. Lee and J. E. Braun, Evaluation of methods for determining demand-limiting setpoint trajectories in buildings using short-term measurements, Building and Environment 43 (2008), pp. $1769-1783$.

[29] K.-H. Lee and J. E. Braun, Model-based demand-limiting control of building thermal mass, Building and Environment 43 (2008), pp. 1633-1646. 